\title{
Evaluation of the Development of Fintech-Served Real Economy Based on Fintech Improvement
}

\author{
Mingxiang Zhou $\mathbb{D}^{1}$ and Xiaoyan Zheng $\mathbb{D}^{2}$ \\ ${ }^{1}$ School of Big Data Application and Economics, Guizhou University of Finance and Economics, Guiyang 550025, China \\ ${ }^{2}$ School of Accounting, Hubei Business College, Wuhan 430000, China \\ Correspondence should be addressed to Xiaoyan Zheng; zhengxiaoyan@hbc.edu.cn
}

Received 16 September 2021; Revised 2 November 2021; Accepted 10 November 2021; Published 26 November 2021

Academic Editor: Daqing Gong

Copyright (c) 2021 Mingxiang Zhou and Xiaoyan Zheng. This is an open access article distributed under the Creative Commons Attribution License, which permits unrestricted use, distribution, and reproduction in any medium, provided the original work is properly cited.

\begin{abstract}
The new generation of information technology (IT) promotes the integration of fintech with the real economy. Existing studies emphasize the relationship between fintech and the real economy over the development level of fintech-served real economy (FtRE). To fill up the gap, this paper explores the evaluation of FtRE based on fintech improvement (FtI). Firstly, an evaluation index system (EIS) was established for fintech service efficiency (FtSE), and FtSE was measured through data envelopment analysis (DEA). Then, fuzzy c-means (FCM) clustering was performed to discretize continuous indices. Drawing on matter-element theories, the authors created the classic domain and node domain of FtRE, as well as the evaluation objects of real economy, calculated the correlation between each factor affecting development level and evaluated development level, and computed the weight coefficient of each index. Finally, the influence of FtI-based FtRE development was empirically analyzed through experiments.
\end{abstract}

\section{Introduction}

Financial systems have many basic functions, including liquidation and payment, financing and equity refinement, transfer of economic resources, risk management, information supply, and incentive provision. The expansion and intellectualization of all these functions are inseparable from fintech improvement (FtI). Under the support of government financial departments, various financial and intermediary service institutions are trying all means (e.g., planning financial products, setting up service platforms, and adjusting/optimizing service models) to push forward the marketization of real economy, aiming to deeply integrate the real economy with fintech improvement $(\mathrm{FtI})$ and financial service mechanism [1-7]. Fintech, known for its huge development potential and high computability with high-quality economic development, brings a new economic form to real economy [8-13]. Fintech development is the key to the development and transformation of the real economy and is an important driver of real economic growth [14-17].
The new generation of information technology (IT) promotes the integration of fintech into the real economy. Hui [18] recognized that the so-called "three dilemmas" (i.e., the conflict in talent supply-demand structure, the loose coupling between talent chain and industrial chain, and the lack of innovative talent policies) bring difficulties to loan financing by small and medium enterprises (SMEs), risk control of banks, and regulation by government departments and proposed to solve these dilemmas by accelerating the deep integration between fintech and cutting-edge ITs (artificial intelligence (AI), big data, and Internet of things (IoT)), as well as the real economy. Using a fixed-effects panel data model of 41 countries, Chatterjee [19] discovered that information and communication technology (ICT) is a major determinant of financial inclusiveness and further highlighted the promoting effect of financial institutions on the growth of each country in the dynamic panel data model, under the deep penetration of ICT. Xiao [20] identified digital fintech as an important direction of revitalizing real economy and deeply analyzed the internal mechanism of the 
digitalization of real economy. From the angle of industrial integration, Xiao [21] discussed the mechanism of improving high-quality economic development through the integration between digital finance and real economy and suggested deeply integrating digital finance and real economy to promote high-quality economic development, in light of the actual situation of China. Maeda [22] investigated the history of real economy business integration by different cultural entities, the integration of key virtual and real devices into fintech, and the organizational strategy for the integration. Li [23] summarized four ways to promote economic development through AI and proposed to better study and prevent potential risks of AI development, while promoting economic development with AI.

The existing studies on FtRE mainly discuss the relationship between fintech and real economy. But, few have evaluated the development level of FtRE by the theory of extenics. To fill up the gap, this paper attempts to evaluate the development of FtI-based FtRE. The main contents are as follows: (1) an evaluation index system (EIS) was established for fintech service efficiency (FtSE), and FtSE was measured through data envelopment analysis (DEA), revealing the correlations of fintech inputs and outputs with real economy development; (2) fuzzy c-means (FCM) clustering was performed to discretize continuous indices, and the development level of FtRE was evaluated against indices like real economic growth, fintech efficiency, economic capital input, human resource input, urbanization level, and degree of openness; (3) the classic domain and node domain of FtRE, as well as the evaluation objects of real economy, were created based on matter-element theories; (4) the correlation between each factor affecting development level and evaluated development level was calculated; (5) the weight coefficient of each index was computed; (6) the influence of FtI-based FtRE development was empirically analyzed through experiments.

\section{FtSE Measurement and Evaluation}

With the development of economics theory, the theory of endogenous growth, which is based on knowledge spillover, emphasizes more on the technical progress involving new concept creation. Fintech improvement plays a critical role in improving the innovation and advancement of production technology in physical industries and directly drives the growth of the real economy. Through linear programming, DEA can effectively evaluate the multi-input, multi-output production units in the same class. To evaluate the association between fintech and real economy, this paper firstly sets up an FtSE index system and measures FtSE by the DEA model.

Let $D M U_{l}$ be a set of composite fintech efficiencies, involving $m$ decision-making units (DMUs), $n$ inputs $a_{i}$, and $w$ outputs $b_{j} ; \alpha_{i}$ be the weight of $a_{i}$; and $\beta_{j}$ be the weight of $b_{j}$. Then, the output-input ratio of FtRE can be described as

$$
g_{l}=\frac{\sum_{j=1}^{w} \beta_{j} b_{j l}}{\sum_{i=1}^{n} \alpha_{i} a_{i l}} .
$$

Suppose all DMUs face constant returns to scale. The composite fintech efficiency can be measured by the following input-oriented linear programming model:

$$
\left\{\begin{array}{l}
\max \sum_{s=1}^{w} \beta_{j} b_{j l} \\
\text { s.t. } \sum_{s=1}^{w} \beta_{j} b_{j l}-\sum_{i=1}^{n} \alpha_{i} a_{i l} \leq 0 . \\
\sum_{i=1}^{n} \alpha_{i} a_{i l}=1
\end{array}\right.
$$

Let $\mu$ be the linear combination coefficient of DMUs and $\omega^{*}$ be the optimal solution to efficiency. Then, formula (2) can be converted to a dual model as follows:

$$
\left\{\begin{array}{l}
\min \omega \\
\text { s.t. } \sum_{j=1}^{m} \mu_{i} a_{i l} \leq \omega a_{i l} . \\
\sum_{j=1}^{m} \mu_{j} b_{j l} \leq b_{j l}
\end{array}\right.
$$

Formula (3) shows $0<\omega^{*} \leq 1$. The efficiency of each DMU needs to be evaluated with a separate programming formula.

In the actual situation, not all DMUs have the optimal production scale. The scale efficiency component might be included in the measuring results of the constructed formulas. To solve the problem, the following constraint was added to formula (3):

$$
\sum_{j=1}^{m} \mu_{j}=1
$$

Based on the panel data of the target DMU, the Malmquist productivity index was adopted to characterize the influence of fintech progress $S I$ and fintech efficiency change TEC on the productivity of real economy: $P I_{M a l}=T E C * S I$. The $P I_{M a l}$ value varies with the periods of the efficient frontier of the real economy. Let $a_{i}$ and $b_{j}$ be the input and output of the DMU, respectively. To ensure the transferability of $P I_{M a l}$, the reference set $R^{T}$ corresponding to a fixed period $T$ can be expressed as

$$
R^{T}=\left\{\left(a_{i}^{T}, b_{j}^{T}\right)\right\} .
$$

Then, the optimal efficient frontier of $T$ is the reference efficient frontier of each period. In this case, $P I_{M a l}$ is a single index:

$$
P I_{\text {Mal }}\left(a^{\phi+1}, b^{\phi+1}, a^{\phi}, b^{\phi}\right)=\frac{D^{T}\left(a^{\phi+1}, b^{\phi+1}\right)}{D^{T}\left(a^{\phi}, b^{\phi}\right)},
$$

where $P I_{M a l}\left(a^{\varphi+1}, b^{\varphi+1}, a^{\varphi}, b^{\varphi}\right)$ is the index from period $\varphi$ to period $\varphi+1$, with $T$ as the fixed reference set, and $D^{T}\left(a^{\varphi}, b^{\varphi}\right)$ be the fintech efficiency calculated by the DEA model of the target DMU, with $T$ as the fixed reference set. The $P I_{M a l}$ values of two adjacent periods are calculated referring to the 
same efficient frontier, while the fintech efficiency change is calculated referring to the efficient frontier of each period:

$$
\eta_{T E C}(\phi, \phi+1)=\frac{D^{\phi+1}\left(a^{\phi+1}, b^{\phi+1}\right)}{D^{\phi+1}\left(a^{\phi}, b^{\phi}\right)} .
$$

The proximity of a fixed frontier to the frontier in period $\varphi+1$ can be calculated by

$$
\frac{D^{T}\left(a^{\phi+1}, b^{\phi+1}\right)}{D^{\phi+1}\left(a^{\phi+1}, b^{\phi+1}\right)} \text {. }
$$

The proximity of a fixed frontier to the frontier in period $\varphi$ can be calculated by

$$
\frac{D^{T}\left(a^{\phi}, b^{\phi}\right)}{D^{\phi}\left(a^{\phi}, b^{\phi}\right)}
$$

The greater the proximities obtained by formulas (8) and (9), the closer the fixed frontier to the frontier in period $\varphi$. Then, technical progress $S I$ can be calculated by formulas (8) and (9):

$$
S I_{T}(\phi, \phi+1)=\frac{D^{T}\left(a^{\phi+1}, b^{\phi+1}\right)}{D^{\phi+1}\left(a^{\phi+1}, b^{\phi+1}\right)} \cdot \frac{D^{\phi}\left(a^{\phi}, b^{\phi}\right)}{D^{T}\left(a^{\phi}, b^{\phi}\right)} .
$$

Hence, the $P I_{M a l}$ with a fixed reference can be decomposed into fintech progress SI and fintech efficiency change TEC:

$$
\begin{aligned}
P I_{\text {Mal }}\left(a^{\phi+1}, b^{\phi+1}, a^{\phi}, b^{\phi}\right) & =\frac{D^{T}\left(a^{\phi+1}, b^{\phi+1}\right)}{D^{T}\left(a^{\phi}, b^{\phi}\right)} \\
& =\frac{D^{\phi+1}\left(a^{\phi+1}, b^{\phi+1}\right) D^{T}\left(a^{\phi+1}, b^{\phi+1}\right) D^{T}\left(a^{\phi+1}, b^{\phi+1}\right)}{D^{T}\left(a^{\phi}, b^{\phi}\right) D^{\phi+1}\left(a^{\phi+1}, b^{\phi+1}\right) D^{\phi}\left(a^{\phi}, b^{\phi}\right)} .
\end{aligned}
$$

Since the reference frontier is fixed for each period, the $P I_{M a l}$ with a fixed reference is transferrable and can be subjected to multiplication:

$$
P I_{M a l}(\phi+1, \phi) \times P I_{M a l}(\phi+2, \phi+1)=P I_{M a l}(\phi+2, \phi) .
$$

where $P I_{\text {Mal }}(\varphi, \varphi+1)$ is the real economy productivity of period $\varphi+1$ to that of period $\varphi$ (if $P I_{M a l}(\varphi, \varphi+1)>1$, the productivity of the real economy is on the rise; if $P I_{M a l}(\varphi$, $\varphi+1)<1$, the productivity of the real economy is on the decline.); $\eta_{T E C}(\varphi, \varphi+1)$ is the fintech efficiency of period $\varphi+1$ to that of period $\varphi$ (if $\eta_{T E C}(\varphi, \varphi+1)>1$, fintech efficiency is on the rise; if $\eta_{T E C}(\varphi, \varphi+1)<1$, fintech efficiency is on the decline); and $\operatorname{SI}(\varphi, \varphi+1)$ is the fintech change of period $\varphi+1$ relative to period $\varphi$ (If $\operatorname{SI}(\varphi, \varphi+1)>1$, fintech is improving; if $\operatorname{SI}(\varphi, \varphi+1)<1$, fintech is not improving).

\section{Index Generation}

This paper sets up an index system for FtI-based FtRE development based on concepts like matrix and fuzzy clustering. To transform the qualitative evaluation into a quantitative problem, the index system needs to make formal descriptions of the index attributes and then discretize the quantitative indices. After obtaining the discretized decision table of index data, it is necessary to construct an identifiable matrix and generate the optimal reduced index system.

The evaluation indices of the development of FtI-based FtRE can be divided into continuous indices and discrete indices. The continuous indices can be discretized through FCM. The main steps of FCM are as follows.
Suppose each area $v_{i}$ among $n$ areas contains $m$ attributes. The area $v_{i}$ corresponding to each index is clustered by FCM to obtain $e$ fuzzy classes. Then, the center of each class is solved to minimize the value function of dissimilar areas. Let $e_{i}$ be the center of fuzzy cluster $i ; \xi_{i j}=\left|e_{i}-a_{j}\right|$ be the Euclidean distance between the data of index $j$ and $e_{i}$; and $l \epsilon$ $[1,+\xi)$ be the weighting index. Then, the value function can be established as

$$
C O\left(V, e_{1}, \ldots, e_{e}\right)=\sum_{i=1}^{e} C O_{i}=\sum_{i=1}^{e} \sum_{j}^{n} v_{i j}^{l} \xi_{i j}^{2},
$$

where

$$
\begin{array}{r}
v_{i j} \in[0,1], \\
\sum_{i=1}^{e} v_{i j}=1, \\
\forall j=1, \ldots, n .
\end{array}
$$

Let $\mu_{j}$ be the Lagrangian multiplier with $m$ constraints. Then, the objective function for the minimization of the value function can be updated as

$$
\begin{aligned}
\overline{C O} & \left(V, e_{1}, \ldots, e_{e}, \mu_{1}, \ldots, \mu_{m}\right) \\
& =C O\left(V, e_{1}, \ldots, e_{e}\right)+\sum_{j=1}^{n} \mu_{j}\left(\sum_{i=1}^{e} v_{i j}-1\right) \\
& =\sum_{i=1}^{e} \sum_{j}^{n} v_{i j}^{l} \xi_{i j}^{2}+\sum_{j=1}^{n} \mu_{j}\left(\sum_{i=1}^{e} v_{i j}-1\right) .
\end{aligned}
$$

Finding the derivative of all input indices, the minimization of formula (13) must satisfy 


$$
\begin{aligned}
e_{i} & =\frac{\sum_{j=1}^{n} v_{i j}^{l} a_{j}}{\sum_{j=1}^{n} v_{i j}^{l}}, \\
v_{i j} & =\frac{1}{\sum_{l=1}^{e}\left(\xi_{i j} / \xi_{l j}\right)^{2 /(l-1)}} .
\end{aligned}
$$

The FCM algorithm terminates under one of the following two conditions: the value function falls below the preset threshold and the variation of the value function in the current iteration relative to the previous iteration is below the preset threshold.

The evaluation of FtI-based FtRE development is nondeterministic polynomial-time (NP) hard. To find the minimum reduced solution to the problem, this paper calculates the kernel attributes for the decision table of identifiable matrix.

First, an identifiable matrix $C$ of the size $n \times n$ was constructed for determining the reduced set of the index system. In the matrix, every element $C_{i j}$ is a subset of index dataset $O$. Let $C_{i j}=\left\{c_{i j 1}, c_{i j 2}, c_{i j 3}, \ldots, c_{i j m}\right\}$. Then, whether index $O_{l}$ belongs to $C_{i j}$ can be judged by

$$
c_{i j l}= \begin{cases}\varphi, & o_{i l}=o_{j l}, \\ O_{l}, & o_{i l} \neq o_{j l} .\end{cases}
$$

\section{Extenics-Based Comprehensive Evaluation}

The matter-element model can abstract and analyze realworld concepts, providing a desirable tool to evaluate FtIbased FtRE. The model can disclose the conflict mechanism between fintech and real economic development and convert the interaction between the two into necessary conditions. Based on the matter-element ideas, the classic domain, node domain, and evaluation object of FtRE development can be established as follows.

Suppose there are $n$ development levels of FtRE, i.e., $R A_{1}$, $R A_{2}, \ldots, R A_{n}$. The development level $R A_{j}$ corresponds to the feature $F E_{i}$. The value range of $u_{j}$ for $R A_{j}$ relative to $F E_{i}$ is $u_{j}$. Then, the matter-element $C D_{j}$ corresponding to $R A_{j}$ can be defined as

$$
C D_{j}=\left(\left(R A_{j}, F E_{i}, u_{j i}\right)\right)=\left[\begin{array}{ccc}
R A_{j} & F E_{1} & u_{j 1} \\
& F E_{2} & u_{j 2} \\
\ldots & \ldots \\
& F E_{m} & u_{j m}
\end{array}\right]=\left[\begin{array}{ccc}
R A_{j} & F E_{1} & \left(x_{j 1}, y_{j 1}\right) \\
& F E_{2} & \left(x_{j 2}, y_{j 2}\right) \\
& \ldots & \ldots \\
& F E_{m} & \left(x_{j m}, y_{j m}\right)
\end{array}\right],
$$

where $C D_{j}$ is the classic domain of FtRE development level. Let $R A_{q}$ be all the development levels of FtRE and $u_{i q}$ be the value range of $R A_{q}$ relative to $F E_{i}$. Then, the node domain $C D_{q}\left(C D_{j} \in C D_{q}\right)$ for $C D_{j}$ can be constructed as

$$
C D_{q}=\left(\left(R A_{q}, F E_{i}, u_{i q}\right)\right)=\left[\begin{array}{ccc}
R A_{q} & F E_{1} & u_{1 q} \\
& F E_{2} & u_{2 q} \\
& \ldots & \cdots \\
& F E_{m} & u_{m q}
\end{array}\right]=\left[\begin{array}{ccc}
Q_{j} & F E_{1} & \left(x_{1 q}, y_{1 q}\right) \\
& F E_{2} & \left(x_{2 q}, y_{2 q}\right) \\
\ldots & \ldots \\
& F E_{m} & \left(x_{m q}, y_{m q}\right)
\end{array}\right] .
$$

Let $Q_{p}$ be an evaluation index and $u_{i}$ be the value of $Q_{p}$ relative to $F E_{i}$. Then, the matter-element of index data can be given by

$$
C D_{p}=\left(\left(R A_{p}, F E_{i}, u_{i}\right)\right)=\left[\begin{array}{ccc}
R A_{p} & F E_{1} & u_{1} \\
& F E_{2} & u_{2} \\
& \cdots & \ldots \\
& F E_{m} & u_{m}
\end{array}\right] .
$$

The degree of correlation between two things can be measured by the correlation coefficient. For overall processing of the chaotic correlation coefficients between fintech and real economy development, this paper quantifies the similarity between the development level of FtI-based FtRE and the index values, trying to further reveal the correlation between fintech and real economy development.

The correlation $C F_{j}\left(h_{i}\right)$ between each factor influencing the development level and each evaluated level of development reflects the membership of each index for real economy to development level $j$. Let $\sigma\left(C F_{j}\left(h_{i}, U_{i j}\right)\right.$ and $\sigma\left(C F_{j}\left(h_{i}, U_{i q}\right)\right.$ be the distances from sample point $h_{i}$ of index data to classic domain $U_{i j}=\left\langle x_{i j}, y_{i j}\right\rangle$ and to node domain $U_{i q}=\left\langle x_{i q}, y_{q j}\right\rangle$, respectively. Then, the correlation function for index $i$ belonging to development level $j$ can be given by 


$$
C F_{j}\left(h_{i}\right)=\left\{\begin{array}{l}
\frac{\sigma\left(h_{i}, U_{i j}\right)}{\sigma\left(h_{i}, U_{i q}\right)-\sigma\left(h_{i}, U_{i j}\right)}, \sigma\left(h_{i}, U_{i q}\right)-\sigma\left(h_{i}, U_{i j}\right) \neq 0 \\
-\rho\left(h_{i}, U_{i j}\right)-1, \rho\left(h_{i}, U_{i p}\right)-\rho\left(h_{i}, U_{i j}\right)=0
\end{array},\right.
$$

where

$$
\sigma(a,\langle x, y\rangle)=\left|a-\frac{x+y}{2}\right|-\frac{1}{2}(y-x) .
$$

Formula (22) shows that correlation $C F_{j}\left(h_{i}\right)$ is the membership of fuzzy set in fuzzy theory. The value range of correlation is the entire real number axis, while that of membership is the closed interval of $[0,1]$. If $C F_{j}\left(h_{i}\right)=$ $C F_{j}\left(h_{i}\right)$, index $h_{i}$ belongs to development level $j$.

The weight of an FtI-based FtRE index represents the importance of the index in the entire EIS. This paper chooses the correlation function to determine the weight of each FtRE index:

$$
s_{i j}\left(h_{i}, U_{i j}\right)=\left\{\begin{array}{ll}
\frac{2\left(h_{i}-x_{i j}\right)}{y_{i j}-x_{i j}}, & h_{i} \leq \frac{x_{i j}+y_{i j}}{2} \\
\frac{2\left(y_{i j}-h_{i}\right)}{y_{i j}-x_{i j}}, & h_{i} \geq \frac{x_{i j}+y_{i j}}{2}
\end{array},\right.
$$

where $h_{i} \in U_{i Q}$. Let $s_{i j-\max }\left(h_{i}, U_{i j-\max }\right)=\max _{j}\left\{s_{i j}\right.$, $\left.\left(h_{i}, U_{i j}\right)\right\}$. If $R E D_{i}$ belongs to a lower development level, then the weight of the corresponding index should be greater:

$$
s_{i}=\left\{\begin{array}{l}
\left(1+s_{i j-\max }\left(h_{i}, U_{i j}\right)\right) \cdot j_{\max }, s_{i j-\max }\left(h_{i}, U_{i j}\right) \geq-0.5, \\
\frac{j_{\max }}{2} s_{i j-\max }\left(h_{i}, U_{i j}\right)<-0.5 .
\end{array}\right.
$$

If $R E D_{i}$ belongs to a greater development level, then the weight of the corresponding index should be smaller:

$$
s_{i}=\left\{\begin{array}{l}
\left(1+s_{i j-\max }\left(h_{i}, U_{i j}\right)\right) \cdot\left(n-j_{\max }+1\right), s_{i j-\max }\left(h_{i}, U_{i j}\right) \geq-0.5, \\
\frac{n-j_{\max }+1}{2}, s_{i j-\max }\left(h_{i}, U_{i j}\right)<-0.5 .
\end{array}\right.
$$

The weight of each index $R E D_{i}$ can be calculated by

$$
\gamma_{i}=\frac{s_{i}}{\sum_{i=1}^{m} s_{i}} .
$$

Let $\gamma_{i l}$ be the weight $R E D_{i}$ solved by the data samples of index $l$. Then, the weight of $R E D_{i}$ equals the mean weights of $m$ samples:

$$
\theta_{i}=\frac{\sum_{l=1}^{m} \gamma_{i l}}{m}
$$

The correlation for evaluation object $E V_{p}$ belonging to evaluation level $j$ can be calculated by

$$
C F_{j}\left(E V_{p}\right)=\sum_{i=1}^{m} \chi_{i} C F_{j}\left(h_{i}\right) .
$$

If $C F_{j i}=\max C F_{j}\left(E V_{p}\right), E V_{p}$ belongs to development level $j$. If $C F_{j}\left(E V_{p}\right)>0$, the evaluation object of real economy satisfies the demand for a development level. In this case, the greater the $C F_{j}\left(E V_{p}\right)$, the more consistent the fintech is with the coordinated development of real economy. If $-1 \leq C F_{j}\left(E V_{p}\right) \leq 0$, the evaluation object of real economy has not satisfied the demand for a development level, but it can meet the demand by adjusting and optimizing the fintech service strategy. The greater the $C_{j}\left(E V_{p}\right)$, the more likely it is for the object to meet that demand through adjustment and optimization. If $C F_{j}\left(E V_{p}\right) \leq-1$, the evaluation object has no ability to satisfy the demand for a development level and little chance to meet that demand through adjustment and optimization. Figure 1 shows the workflow of our algorithm.

\section{Experiments and Result Analysis}

Experiments were carried out to empirically analyze the factors affecting the development of FtI-based FtRE. The variables were selected reasonably based on the above analysis: real economic growth, fintech efficiency, economic capital input, human resource input, urbanization level, and degree of openness. The explanatory variables are the real economic growth $\mathrm{REG}_{i s}$ and fintech efficiency $\mathrm{FTE}_{i s}$. Let $\mathrm{CIV}_{\text {is }}$ and $\mathrm{HRIV}_{\text {is }}$ be the economic capital input and human resource input of the study area, respectively; $\mathrm{UL}_{i s}$ and $\mathrm{OTO}_{i s}$ be the urbanization level and degree of openness, respectively; $\eta_{i}$ be the intercept of individual heterogeneity of subarea $i$; and $\mathrm{PT}_{i s}$ be the random disturbance term. Then, this paper sets up the analysis model for subarea $i$ in years:

$$
R E G_{i s}=\psi_{1} F_{T E}+\psi_{2} C I V_{i s}+\psi_{3} H R I V_{i s}+\psi_{4} U L_{i s}+\psi_{5} O T O_{i s}+\eta_{i}+P T_{i s} .
$$

To facilitate the interpretation of the analysis model and consider the possible heteroscedasticity of influencing factors, the log of formula (30) was taken:

$$
\ln R E G_{i s}=\psi_{1} \ln F T E_{i s}+\psi_{2} \ln C I V_{i s}+\psi_{3} \ln H R I V_{i s}+\psi_{4} \ln U L_{i s}+\psi_{5} \ln O T O_{i s}+\eta_{i}+P T_{i s} .
$$




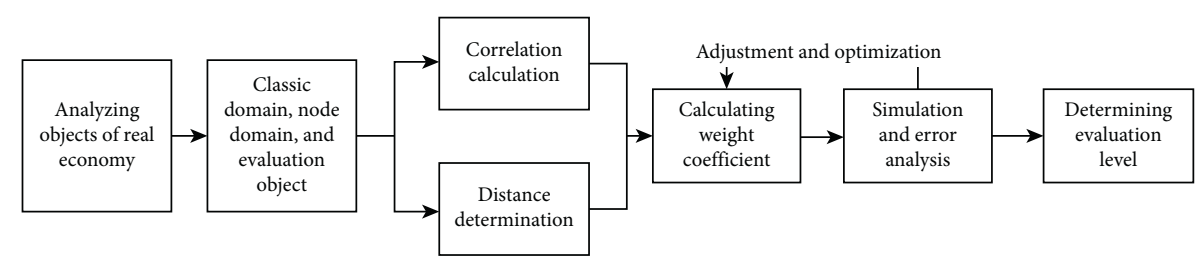

Figure 1: Workflow of evaluation.

The data on the five indices were divided to the level of entire area and the level of subarea for the empirical test. On the first level, the sample data of the indices in the 30 districts and counties were analyzed empirically to disclose the influence of fintech services on real economic development in the whole region. On the subarea level, the study area was divided into five parts, east, south, west, north, and center, and the influence of fintech services on real economic development was investigated area by area.

Referring to existing studies on how fintech services affect real economic development, five evaluation levels were defined: germination phase, initial development phase, moderate development phase, advanced development phase, and maturity phase. Referring to the actual development levels of FtI-based FtRE in major cities across China, the threshold and weight of each index were computed by formula (26). Table 1 lists the value range of each index.

The composite correlation of each index and each development level was calculated for each of the five subareas, using the sample data on the indices in 2019. Table 2 lists the evaluated level of real economic development in each subarea, which displays the evaluated result and development trend of real economy. The east area had a correlation of 0.5721 , indicating that the real economic development belongs to level 3 (moderate development phase). The north and central areas had a correlation of 0.5275 and 0.5756 , respectively, suggesting that both areas belong to the moderate development phase. Similarly, the west area belongs to the initial development phase, while the south area is stepping into the advanced development phase. The evaluated results were close to the actual situation in the five subareas. Hence, our evaluation model for real economic development is reasonable and feasible, laying the basis for the assessment and forecast of future FtRE development level in each subarea of the study area.

The proposed model was subjected to the consistency test to judge if the evaluated results echo with the actual situation. Table 3 lists the simulated and actual values of the consistency test. The relative error between the two values reflects the reliability and accuracy of our model. The test results show that the relative error between the simulated and actual values of the selected indices was always smaller than 0.05 , meeting the needs of the consistency test. Hence, our model is feasible and effective in simulating regional FtRE development.

Based on MaxDEA 8, a superefficiency DEA (SEDEA) model was chosen to measure the FtSE values of the five subareas from 2009 to 2020, with 2008 as the reference year. The measured results are given in Table 4 .
As shown in Table 4, from 2009 to 2020, the FtSEs of most subareas increased year by year. Compared with the reference year, the east area was the only area with an FtSE $>1$ in 2009. That is, the $2009 \mathrm{FtSE}$ in any other subarea failed to reach the efficient frontier of 2008. The main reason is that the 2008 financial crisis greatly suppresses real economic development and lowers the output of fintech services. After 2009, the FtSE of every subarea increased steadily. The fintech services in the central area started low and developed slowly. The FtSE of the central area did not reach 1 until 2015. The fintech services in all subareas developed stably, without being affected by uncertain factors.

Taking 2008 as the fixed reference year, the Malmquist productivity indices were calculated and used to analyze the change law of FtSE in each of the five subareas in 2020. In addition, the FtSE change in each subarea was decomposed to further explore the effects of technical progress, technical efficiency, and real economy scale on FtSE variation.

Table 5 presents the measured Malmquist productivity indices of FtSE. From 2009 to 2020, the mean FtSE in the study area increased by around $10 \%$. Due to the 2008 global financial crisis, the FtSE of the study area increased greatly from 2008 to 2009. As a result, the annual growth rate peaked in 2009, reaching 59.14\%. The Malmquist productivity index was also very high in that year. Before 2013, the south and central areas had a Malmquist index smaller than 1, indicating that the two subareas fail to reach ideal development efficiency of fintech services prior to 2013. The most probable reason is the regional policy on real economic development.

The change law of FtSE in each of the five subareas in 2009-2020 can be derived from the mean Malmquist productivity index, and the mean of each component of the Malmquist productivity index was decomposed in terms of technical progress, technical efficiency, and real economy scale (Table 6).

As shown in Table 4, the Malmquist productivity index of FtRE was relatively high in west and south areas. The fintech efficiency of the west area mainly improves out of the growing technical efficiency, while that of the south area mainly improves out of technical progress. Of the 12 subareas, five subareas saw real economy scale change by less than 1. In these subareas, when the technical input is fixed for fintech services, the inputs might be redundant or the outputs might be insufficient.

Before regression analysis of panel data on index samples, this paper carries out the unit root test on the stability of the panel data, aiming to prevent spurious regression. Table 7 presents the test results. Prior to multivariate regression on the panel data, the type of regression model was 
TABLE 1: Value range for each index.

\begin{tabular}{|c|c|c|c|c|c|}
\hline Index layer & $\mathrm{FTE}_{i s}$ & $\mathrm{CIV}_{\text {is }}$ & $\mathrm{HRIV}_{\text {is }}$ & $\mathrm{UL}_{i s}$ & $\mathrm{OTO}_{i s}$ \\
\hline Germination phase & {$[22,23)$} & {$[0,0.3)$} & {$[400,325)$} & {$[0.2,0.35)$} & {$[0,0.2)$} \\
\hline Initial development phase & {$[23,35)$} & {$[0.3,0.5)$} & {$[325,260)$} & {$[0.35,0.45)$} & {$[0.2,0.4)$} \\
\hline Moderate development phase & {$[35,45)$} & {$[0.5,0.7)$} & {$[260,170)$} & {$[0.45,0.55)$} & {$[0.4,0.6)$} \\
\hline Advanced development phase & {$[45,55)$} & {$[0.7,0.9)$} & {$[170,90)$} & {$[0.55,0.65)$} & {$[0.6,0.8)$} \\
\hline Maturity phase & {$[55,75]$} & {$[0.9,1]$} & {$[90,10]$} & {$[0.65,0.7]$} & {$[0.8,1]$} \\
\hline Index weight & 0.255 & 0.153 & 0.142 & 0.224 & 0.226 \\
\hline
\end{tabular}

TABLE 2: Evaluated level of real economic development in each subarea.

\begin{tabular}{|c|c|c|c|c|c|}
\hline Correlation & East area & West area & South area & North area & Central area \\
\hline Germination phase & -1.5736 & -0.6735 & -0.7312 & -1.3726 & -1.0254 \\
\hline Initial development phase & -0.6782 & 0.4534 & -1.7253 & -0.9521 & -0.8147 \\
\hline Moderate development phase & 0.5721 & -0.4723 & -0.7268 & 0.5275 & 0.5756 \\
\hline Advanced development phase & -0.5476 & -1.5631 & 0.3177 & -0.9523 & -0.8562 \\
\hline Maturity phase & -1.4885 & -1.7527 & -1.8672 & -1.6537 & -1.6521 \\
\hline Level & Initial & Initial & Moderate & Moderate & Moderate \\
\hline Trend & Weakly advanced & Moderately moderate & Weakly germinated & Weakly advanced & Weakly initialized \\
\hline
\end{tabular}

TABLE 3: Simulated and actual values of the consistency test.

\begin{tabular}{|c|c|c|c|c|c|c|c|c|c|c|c|c|c|}
\hline & Year & 2009 & 2010 & 2011 & 2012 & 2013 & 2014 & 2015 & 2016 & 2017 & 2018 & 2019 & 2020 \\
\hline \multirow[b]{2}{*}{$F T E_{i s}$} & Simulated value & 22.32 & 23.25 & 25.13 & 26.32 & 26.525 & 27.37 & 27.64 & 28.26 & 29.61 & 30.47 & 31.25 & 31.78 \\
\hline & Actual value & 22.47 & 23.62 & 24.27 & 25.79 & 25.63 & 26.58 & 27.25 & 28.97 & 29.34 & 30.87 & 31.51 & 32.23 \\
\hline \multirow{2}{*}{$C I V_{\text {is }}$} & Simulated value & 0.51 & 0.52 & 0.54 & 0.56 & 0.53 & 0.57 & 0.61 & 0.59 & 0.62 & 0.64 & 0.65 & 0.61 \\
\hline & Actual value & 0.47 & 0.49 & 0.51 & 0.52 & 0.54 & 0.56 & 0.58 & 0.63 & 0.65 & 0.66 & 0.69 & 0.70 \\
\hline \multirow{2}{*}{$H R I V_{i s}$} & Simulated value & 164.17 & 165.1 & 167.6 & 171.4 & 172.8 & 177.9 & 179.2 & 181.3 & 182.5 & 183.7 & 185.2 & 186.9 \\
\hline & Actual value & 160 & 162 & 169 & 171 & 173 & 178 & 182 & 184 & 186 & 187 & 189 & 190 \\
\hline \multirow{2}{*}{$U L_{i s}$} & Simulated value & 0.51 & 0.52 & 0.54 & 0.56 & 0.53 & 0.57 & 0.61 & 0.59 & 0.62 & 0.64 & 0.65 & 0.61 \\
\hline & Actual value & 0.47 & 0.49 & 0.51 & 0.52 & 0.54 & 0.56 & 0.58 & 0.63 & 0.65 & 0.66 & 0.69 & 0.70 \\
\hline \multirow{2}{*}{$\mathrm{OTO}_{i s}$} & Simulated value & 0.41 & 0.45 & 0.53 & 0.56 & 0.57 & 0.59 & 0.61 & 0.63 & 0.64 & 0.67 & 0.68 & 0.71 \\
\hline & Actual value & 0.43 & 0.48 & 0.49 & 0.51 & 0.52 & 0.54 & 0.56 & 0.57 & 0.59 & 0.62 & 0.63 & 0.64 \\
\hline
\end{tabular}

TABLE 4: FtSE values obtained by SEDEA.

\begin{tabular}{|c|c|c|c|c|c|}
\hline Year & East area & West area & South area & North area & Central area \\
\hline 2009 & 1.1024 & 0.8147 & 0.7243 & 0.6475 & 0.5012 \\
\hline 2010 & 1.1752 & 0.8253 & 0.7456 & 0.6514 & 0.5485 \\
\hline 2011 & 1.2351 & 0.9453 & 0.8423 & 0.7253 & 0.6752 \\
\hline 2012 & 1.6523 & 0.9943 & 0.9459 & 0.9561 & 0.7943 \\
\hline 2013 & 1.8516 & 1.1731 & 1.1542 & 1.2385 & 0.8132 \\
\hline 2014 & 1.9523 & 1.2682 & 1.3754 & 1.4952 & 0.9354 \\
\hline 2015 & 2.1675 & 1.9735 & 1.6789 & 1.6125 & 1.2154 \\
\hline 2016 & 2.6056 & 2.3453 & 1.8212 & 1.8512 & 1.3786 \\
\hline 2017 & 3.2597 & 2.4521 & 1.9243 & 1.9453 & 1.4765 \\
\hline 2018 & 3.6351 & 2.5785 & 2.3756 & 2.2571 & 1.5912 \\
\hline 2019 & 4.9567 & 2.9352 & 2.6746 & 2.3189 & 1.6586 \\
\hline 2020 & 5.6242 & 3.4515 & 2.9134 & 2.4456 & 1.8234 \\
\hline
\end{tabular}

TABLE 5: Malmquist productivity indices of FtSE.

\begin{tabular}{cccccc}
\hline Year & East area & West area & South area & North area & Central area \\
\hline 2010 & 1.0241 & 0.9013 & 0.9114 & 0.9478 & 0.9144 \\
2010 & 1.1723 & 0.9651 & 0.9534 & 1.0865 & 0.9912 \\
2011 & 1.3561 & 1.1756 & 2.1735 & 1.0153 & 0.8894 \\
2012 & 1.3156 & 1.2894 & 0.9849 & 1.9842 & 0.9849 \\
\hline
\end{tabular}


TABLE 5: Continued.

\begin{tabular}{|c|c|c|c|c|c|}
\hline Year & East area & West area & South area & North area & Central area \\
\hline 2013 & 1.4561 & 1.2517 & 0.9741 & 1.2486 & 0.7156 \\
\hline 2014 & 1.5579 & 1.2654 & 1.1562 & 1.4725 & 1.1563 \\
\hline 2015 & 1.6158 & 1.3891 & 1.2145 & 1.5849 & 1.3168 \\
\hline 2016 & 1.962 & 1.2156 & 1.4948 & 1.5132 & 1.4489 \\
\hline 2017 & 1.7234 & 1.1844 & 1.3489 & 1.6894 & 1.5123 \\
\hline 2018 & 1.8641 & 1.2498 & 1.0376 & 1.5612 & 1.2894 \\
\hline 2019 & 1.5327 & 1.135 & 1.2843 & 1.6891 & 1.4927 \\
\hline 2020 & 1.2461 & 1.3489 & 1.5763 & 1.7563 & 1.9152 \\
\hline
\end{tabular}

TABLE 6: Mean of the Malmquist productivity index and mean of its components.

\begin{tabular}{|c|c|c|c|c|}
\hline Subarea & Malmquist productivity index & Technical progress & Technical efficiency & Real economy scale \\
\hline East area $\mathrm{A}$ & 1.1752 & 1.5423 & 1.0534 & 0.9753 \\
\hline East area $\mathrm{B}$ & 1.1352 & 1.2513 & 0.9846 & 0.9079 \\
\hline East area $\mathrm{C}$ & 1.1825 & 1.6421 & 1.0421 & 1.0023 \\
\hline West area $\mathrm{A}$ & 1.1607 & 1.2354 & 1.2253 & 1.1086 \\
\hline West area B & 1.2354 & 1.0156 & 1.2469 & 1.2853 \\
\hline West area $\mathrm{C}$ & 1.3356 & 1.0215 & 1.3205 & 1.2371 \\
\hline South area $\mathrm{A}$ & 1.2876 & 1.2374 & 1.2012 & 1.0036 \\
\hline South area B & 1.2354 & 1.2562 & 1.2337 & 1.1725 \\
\hline South area C & 1.2672 & 1.4551 & 1.5961 & 1.0402 \\
\hline North area A & 1.1809 & 1.5423 & 1.4652 & 0.9617 \\
\hline North area B & 1.2532 & 1.2355 & 1.2453 & 1.0352 \\
\hline North area $\mathrm{C}$ & 1.1742 & 1.2576 & 1.3247 & 1.0514 \\
\hline Central area $\mathrm{A}$ & 1.10359 & 1.1453 & 1.1576 & 0.9976 \\
\hline Central area B & 1.0585 & 1.1762 & 1.0653 & 0.9246 \\
\hline Central area $\mathrm{C}$ & 1.1473 & 1.2571 & 1.1326 & 1.0384 \\
\hline
\end{tabular}

TABLE 7: Unit root test results.

\begin{tabular}{|c|c|c|c|c|c|c|}
\hline Variables & Study area & East area & West area & South area & North area & Central area \\
\hline $\ln R E G$ & $\begin{array}{c}7.2536 \\
(1.0000)\end{array}$ & $\begin{array}{c}3.9672 \\
(1.0000)\end{array}$ & $\begin{array}{l}5.24623 \\
(0.9999)\end{array}$ & $\begin{array}{l}2.35721 \\
(1.0000)\end{array}$ & $\begin{array}{c}3.8932 \\
(1.0000)\end{array}$ & $\begin{array}{c}4.3561 \\
(0.9999)\end{array}$ \\
\hline $\ln F T E$ & $\begin{array}{l}-0.8175 \\
(0.1726)\end{array}$ & $\begin{array}{l}-1.2725 \\
(0.1052)\end{array}$ & $\begin{array}{c}-0.7625 \\
(0.76255)\end{array}$ & $\begin{array}{l}-0.7541 \\
(1.0000)\end{array}$ & $\begin{array}{l}-1.9152 \\
(1.0000)\end{array}$ & $\begin{array}{c}-0.1562 \\
(1.0000)\end{array}$ \\
\hline $\ln C I V$ & $\begin{array}{c}4.9231 \\
(1.0000)\end{array}$ & $\begin{array}{c}1.5762 \\
(0.3075)\end{array}$ & $\begin{array}{c}3.7532 \\
(0.9996)\end{array}$ & $\begin{array}{c}3.7521 \\
(0.9999)\end{array}$ & $\begin{array}{c}3.1546 \\
(0.9997)\end{array}$ & $\begin{array}{c}3.7812 \\
(0.9998)\end{array}$ \\
\hline $\ln H R I V$ & $\begin{array}{c}3.4721 \\
(0.9984)\end{array}$ & $\begin{array}{c}2.0754 \\
(0.9852)\end{array}$ & $\begin{array}{c}0.4552 \\
(0.9975)\end{array}$ & $\begin{array}{c}0.0235 \\
(0.9803)\end{array}$ & $\begin{array}{c}0.4531 \\
(0.5111)\end{array}$ & $\begin{array}{c}0.9612 \\
(1.0000)\end{array}$ \\
\hline $\ln U L$ & $\begin{array}{c}3.5763 \\
(0.9721)\end{array}$ & $\begin{array}{c}1.7423 \\
(0.9563)\end{array}$ & $\begin{array}{c}0.3376 \\
(0.5235)\end{array}$ & $\begin{array}{c}0.3575 \\
(0.9527)\end{array}$ & $\begin{array}{c}0.4756 \\
(0.0952)\end{array}$ & $\begin{array}{c}0.4561 \\
(1.0000)\end{array}$ \\
\hline $\ln O T O$ & $\begin{array}{l}-4.6759 \\
(0.6752)\end{array}$ & $\begin{array}{l}-0.8783 \\
(0.1875)\end{array}$ & $\begin{array}{c}0.3514 \\
(0.6308)\end{array}$ & $\begin{array}{l}-1.3557 \\
(0.1235)\end{array}$ & $\begin{array}{l}-1.8754 \\
(0.1242)\end{array}$ & $\begin{array}{l}-1.9168 \\
(0.1851)\end{array}$ \\
\hline$\triangle \ln R E G$ & $\begin{array}{l}-6.7315 \\
(0.0000)\end{array}$ & $\begin{array}{l}-3.5840 \\
(0.0001)\end{array}$ & $\begin{array}{l}-2.5354 \\
(0.0052)\end{array}$ & $\begin{array}{l}-3.4852 \\
(0.0157)\end{array}$ & $\begin{array}{c}-3.456 \\
(0.0124)\end{array}$ & $\begin{array}{l}-3.5677 \\
(0.0251)\end{array}$ \\
\hline$\Delta \ln F T E$ & $\begin{array}{l}-4.0824 \\
(0.0000)\end{array}$ & $\begin{array}{l}-2.8159 \\
(0.0015)\end{array}$ & $\begin{array}{l}-3.5729 \\
(0.0005)\end{array}$ & $\begin{array}{l}-3.4785 \\
(0.0003)\end{array}$ & $\begin{array}{l}-3.5751 \\
(0.0006)\end{array}$ & $\begin{array}{l}-3.7851 \\
(0.0004)\end{array}$ \\
\hline$\Delta \ln C I V$ & $\begin{array}{l}-4.5431 \\
(0.0000)\end{array}$ & $\begin{array}{l}-2.3153 \\
(0.0125)\end{array}$ & $\begin{array}{l}-1.6217 \\
(0.0572)\end{array}$ & $\begin{array}{r}-3.5242 \\
(0.0005)\end{array}$ & $\begin{array}{l}-3.7894 \\
(0.0006)\end{array}$ & $\begin{array}{l}-3.5412 \\
(0.0007)\end{array}$ \\
\hline$\Delta \ln H R I V$ & $\begin{array}{l}-4.0271 \\
(0.0000)\end{array}$ & $\begin{array}{l}-2.0576 \\
(0.0235)\end{array}$ & $\begin{array}{l}-2.4276 \\
(0.0023)\end{array}$ & $\begin{array}{l}-2.0575 \\
(0.0212)\end{array}$ & $\begin{array}{l}-2.3541 \\
(0.0023)\end{array}$ & $\begin{array}{l}-2.4512 \\
(0.0025)\end{array}$ \\
\hline$\Delta \ln U L$ & $\begin{array}{l}-4.2785 \\
(0.0000)\end{array}$ & $\begin{array}{l}-2.5136 \\
(0.0049)\end{array}$ & $\begin{array}{l}-2.4351 \\
(0.0076)\end{array}$ & $\begin{array}{l}-2.3725 \\
(0.0090)\end{array}$ & $\begin{array}{l}-2.2864 \\
(0.0091)\end{array}$ & $\begin{array}{l}-2.7546 \\
(0.0085)\end{array}$ \\
\hline$\Delta \ln O T O$ & $\begin{array}{l}-5.6724 \\
(0.0000) \\
\end{array}$ & $\begin{array}{l}-3.7685 \\
(0.0003)\end{array}$ & $\begin{array}{l}-2.6753 \\
(0.0045)\end{array}$ & $\begin{array}{l}-3.5672 \\
(0.0002)\end{array}$ & $\begin{array}{l}-3.7851 \\
(0.0003)\end{array}$ & $\begin{array}{l}-3.5452 \\
(0.0002)\end{array}$ \\
\hline
\end{tabular}

determined to ensure the realistic nature of regression results. This paper chooses the random effects model suitable for dealing with the scenario that explanatory variables are not correlated with the intercept terms, which changes from individual to individual, and carries out a Hausman test on the panel data. The regression results are recorded in Table 8. 
TABLE 8: Regression results.

\begin{tabular}{|c|c|c|c|c|c|c|}
\hline Variable & Global & East & West & South & North & Central \\
\hline $\ln R E G$ & $\begin{array}{c}0.1521^{* * *} \\
\quad(5.27)\end{array}$ & $\begin{array}{c}0.1753^{*} \\
(1.86)\end{array}$ & $\begin{array}{c}0.0283 \\
(0.89)\end{array}$ & $\begin{array}{c}0.1942^{* * *} \\
(2.32)\end{array}$ & $\begin{array}{c}0.2357^{*} \\
(0.89)\end{array}$ & $\begin{array}{c}0.2621 \\
(0.75)\end{array}$ \\
\hline $\ln F T E$ & $\begin{array}{c}0.2135^{* * *} \\
\quad(4.05)\end{array}$ & $\begin{array}{c}0.2753^{* *} \\
(2.37)\end{array}$ & $\begin{array}{c}0.4375^{* * *} \\
\quad(9.35)\end{array}$ & $\begin{array}{c}0.0672^{* * *} \\
(2.03)\end{array}$ & $\begin{array}{c}0.0752^{*} \\
(2.35)\end{array}$ & $\begin{array}{c}0.3242 \\
(2.47)\end{array}$ \\
\hline $\ln C I V$ & $\begin{array}{c}0.8235^{* * *} \\
\quad(4.15)\end{array}$ & $\begin{array}{c}0.6015^{*} \\
(5.27)\end{array}$ & $\begin{array}{c}0.1576^{* * *} \\
\quad(4.08)\end{array}$ & $\begin{array}{c}0.9542^{* * *} \\
(8.96)\end{array}$ & $\begin{array}{c}0.9751^{*} \\
(5.63)\end{array}$ & $\begin{array}{c}0.8674 \\
(5.72)\end{array}$ \\
\hline $\ln H R I V$ & $\begin{array}{c}1.3576^{* * *} \\
(5.27)\end{array}$ & $\begin{array}{c}0.1521^{*} \\
(5.27)\end{array}$ & $\begin{array}{c}1.2375^{* * *} \\
(4.92)\end{array}$ & $\begin{array}{c}2.0354^{* * *} \\
\quad(5.27)\end{array}$ & $\begin{array}{c}1.7535^{*} \\
(4.08)\end{array}$ & $\begin{array}{c}1.9508 \\
(5.71)\end{array}$ \\
\hline $\ln U L$ & $\begin{array}{l}-0.0157 \\
(-0.62)\end{array}$ & $\begin{array}{c}-0.0752 \\
(-0.74)\end{array}$ & $\begin{array}{c}-1.085^{* * *} \\
(-0.85)\end{array}$ & $\begin{array}{c}3.2851^{* * *} \\
(-1.35)\end{array}$ & $\begin{array}{l}3.5785 \\
(-0.76)\end{array}$ & $\begin{array}{l}2.1512 \\
(-1.08)\end{array}$ \\
\hline Constant term & $\begin{array}{c}2.1572 \\
(1.57)\end{array}$ & $\begin{array}{c}2.9135^{*} \\
(1.76)\end{array}$ & $\begin{array}{c}-1.085^{* * *} \\
(5.35)\end{array}$ & $\begin{array}{c}3.21521^{* * *} \\
\quad(4.67)\end{array}$ & $\begin{array}{c}2.1572^{* * *} \\
\quad(2.35)\end{array}$ & $\begin{array}{l}1.5721 \\
(3.76)\end{array}$ \\
\hline Observation & 310 & 120 & 90 & 120 & 130 & 80 \\
\hline R-square & 0.9675 & 0.7512 & 0.8559 & 0.8675 & 0.7653 & 0.9785 \\
\hline
\end{tabular}

${ }^{*} p<0.1,{ }^{* *} p<0.5$ and ${ }^{* * *} p<0.1$.

\section{Conclusions}

This paper mainly investigates the evaluation of FtI-based FtRE development. After setting up an FtSE index system, the DEA model was introduced to measure FtSE. The continuous indices were discretized through FCM. Then, the matter-element ideas were referred to construct the classic domain and node domain of FtRE and evaluation object of real economy. Then, the authors calculated the correlation between each factor affecting development level and evaluated development level and derived the index weights. After that, the influence of FtI-based FtRE development was empirically analyzed through experiments. The development levels of real economy in five subareas were evaluated, yielding the evaluation results on real economy and its development trend. The proposed model was then subjected to the consistency test. The results demonstrate the feasibility and effectiveness of our model in simulating regional FtRE development. Furthermore, a SEDEA model was adopted to compute FtSE values and their Malmquist productivity indices, and the panel data on evaluation indices were subjected to the unit root test and regression analysis. The relevant test results and analysis outcomes were presented clearly.

\section{Data Availability}

The data used to support the findings of this study are available from the corresponding author upon request.

\section{Conflicts of Interest}

The authors declare that they have no conflicts of interest.

\section{References}

[1] W. Li, "Applications of financial technology in foreign exchange market," E3S Web of Conferences, vol. 233, 2021.

[2] D. Liu, M. Zhao, and H. Xu, "Financial technology intelligent intrusion detection system based on financial data feature extraction and DNNs," in Proceedings of the 2021 Third International Conference On Intelligent Communication
Technologies And Virtual Mobile Networks (ICICV), pp. 8993, Tirunelveli, India, February 2021.

[3] L.-Y. Jiang, C.-J. Kuo, Y.-H. Wang et al., "A transparentlysecure and robust stock data supply framework for financialtechnology applications," in Proceedings of the 3rd International Asian Conference On Intelligent Information And Database Systems, pp. 616-629, Daegu, Korea, April 2021.

[4] S. A. Renu and B. G. Banik, "Implementation of a secure ridesharing DApp using smart contracts on Ethereum blockchain," International Journal of Safety and Security Engineering, vol. 11, no. 2, pp. 167-173, 2021.

[5] H. Haotian, Y. Dong, and Y. Li, "The analyse of financial technology industry and case study of some typical companies," in Proceedings of the 2021 12th International Conference On E-Education, E-Business, E-Management, and E-Learning, pp. 323-332, Tokyo Japan, January 2021.

[6] D. Rojas-Torres, N. Kshetri, M. M. Hanafi, and S. Kouki, "Financial technology in Latin America," IT Professional, vol. 23, no. 1, pp. 95-98, 2021.

[7] N. Hewa Wellalage, A. I. Hunjra, R. Manita, and S. M. Locke, "Information communication technology and financial inclusion of innovative entrepreneurs," Technological Forecasting and Social Change, vol. 163, Article ID 120416, 2021.

[8] L. Ou and L. Chen, "An improved deep learning algorithm for risk prediction of corporate internet reporting," Revue d'Intelligence Artificielle, vol. 34, no. 4, pp. 437-444, 2020.

[9] Z. Xie, Y. Chen, B. Yu, L. Wu, S. Chen, and Y. Li, "Research on evaluation model of regional financial science and technology development based on local variable weight," Journal of Physics: Conference Series, vol. 1769, no. 1, Article ID 012053, 2021.

[10] R. Doszhan, A. Nurmaganbetova, R. Pukala, G. Yessenova, S. Omar, and A. Sabidullina, "New challenges in the financial management under the influence of financial technology," E3S Web of Conferences, vol. 159, Article ID 04015, 2020.

[11] G. Suseendran, E. Chandrasekaran, D. Akila, and A. Sasi Kumar, "Banking and FinTech (financial technology) embraced with IoT device," in Data Management, Analytics And Innovation, pp. 197-211, Springer, Berlin, Germany, 2020.

[12] Y. C. Wu, L. Yan, and Z. J. Xie, "Spatial dependence between financial development and growth of real economy: an empirical study based on spatial econometric model," in Proceedings of the 8th International Symposium on Project Management, pp. 107-117, Amman, Jordan, September 2020. 
[13] H. Wang, "An effect analysis model for corporate marketing mix based on artificial neural network," Ingénierie des Systèmes d'Information, vol. 25, no. 5, pp. 579-587, 2020.

[14] A. N. Zhilkina, "Organization of financial monitoring activity at an enterprise of real sector of economy," in Proceedings of the 2010 International Conference on Management Science \& Engineering 17th Annual Conference Proceedings, pp. 11111114, Melbourne, VIC, Australia, November 2010.

[15] E. Pesotskaya, A. Khakimov, and I. Alpackaya, "Methodology for assessing and improving the competitiveness of enterprises in the real sector of the economy," E3S Web of Conferences, vol. 91, Article ID 08059, 2019.

[16] Y. Deng and H. Wang, "Research on industrial integration and upgrading of artificial intelligence and real economy," in Proceedings of the 2019 12th International Conference On Intelligent Computation Technology And Automation (ICICTA), pp. 692-695, Xiangtan, China, October 2019.

[17] Y. Shang, "Research on the relationship between virtual economy and real economy development in China," Journal of Physics: Conference Series, vol. 1237, no. 2, Article ID 022098, 2019.

[18] F. Hui, "Application of big data blockchain technology in financial support of real economy," Journal of Physics: Conference Series, vol. 1955, no. 1, Article ID 012018, 2021.

[19] A. Chatterjee, "Financial inclusion, information and communication technology diffusion, and economic growth: a panel data analysis," Information Technology for Development, vol. 26, no. 3, pp. 607-635, 2020.

[20] X. Y. Xiao, "Research on the revitalization of real economy based on digital technology," in Proceedings of the 2020 Management Science Informatization and Economic Innovation Development Conference (MSIEID), pp. 73-76, Guangzhou, China, December 2020.

[21] X. Y. Xiao, "Research on the integration of digital economy and real economy to promote high-quality economic development," in Proceedings of the 2020 Management Science Informatization And Economic Innovation Development Conference (MSIEID), pp. 8-11, Guangzhou, China, December 2020.

[22] N. Maeda, "Managing the real business for digital economySONY's trial on managing the real and virtual," in Proceedings of the 2000 IEEE International Conference on Management of Innovation and Technology. ICMIT 2000.'Management in the 21st Century'(Cat. No. 00EX457), pp. 616-621, Singapore, November 2000.

[23] B. Li, "Dynamic evaluation and system coordination degree of the integration of artificial intelligence and real economy," Complexity, vol. 2021, Article ID 5539793, 9 pages, 2021. 